\title{
The Hippo pathway in colorectal cancer
}

\author{
Piotr M. Wierzbicki, Agnieszka Rybarczyk \\ Department of Histology, Faculty of Medicine, Medical University of Gdansk, Gdansk, Poland
}

\begin{abstract}
Colorectal cancer (CRC) is one the most frequently diagnosed neoplastic diseases worldwide. Currently, aside from traditional chemotherapy, advanced CRCs are treated with modern drugs targeting cellular components such as epithelial growth factor receptor (EGFR). Since up to $70 \%$ of metastasized CRCs are drug resistant, the description of recent progress in cellular homeostasis regulation may shed new light on the development of new molecular targets in cancer treatment. The Hippo pathway has recently become subject of intense investigations since it plays a crucial role in cell proliferation, differentiation, apoptosis and tumourigenesis. Components of the Hippo pathway are deregulated in various human malignancies, and expression levels of its major signal transducers were proposed as prognostic factors in colorectal cancer. In this review we focused on recent data regarding Hippo pathway, its up-stream signals and down-stream effectors. Hippo negatively regulates its major effectors, YAP1 and TAZ kinases, which act as transcriptional co-activators inducing expression of genes involved not only in tissue repair and proliferation but are also oncoproteins involved in tumour development and progression. The deregulation of Hippo pathway components was found in many malignancies.

The interactions between Hippo and Wnt $/ \beta$-catenin signalling, crucial in the maintenance of cell homeostasis, have been described in relation to the control of intestinal stem cell proliferation and CRC development. The recently discovered positive feedback loop between activated YAP1 and increased EGFR/KRAS signalling found in oesophageal, ovarian and hepatocellular cancer has been related to the CRC progression and resistance to EGFR inhibitors during CRC therapy. (Folia Histochemica et Cytobiologica 2015, Vol. 53, No. 2, 105-119)
\end{abstract}

Key words: CRC; Hippo pathway; YAP1/TAZ; Wnt signalling; EGFR/KRAS; intestinal stem cells

\begin{abstract}
Abbreviations: AJ — adherent junction, AMOT angiomotin, APC - adenomatous polyposis coli, AREG - amphiregulin, Axl — Axl receptor tyrosine kinase, BMI1 - BMI1 polycomb ring finger proto-oncogene, - TrCP - beta-transducin repeat containing E3 ubiquitin protein ligase, CK1 - casein kinase 1, $\mathrm{CRC}$ - colorectal cancer, CTGF - connective tissue growth factor, DSS - dextran sodium sulphate, DVL - Dishevelled protein, ECM - extracellular matrix, EGFR - epithelial growth factor receptor, EMT epithelial-to-mesenchymal transition, FAT - FAT atypical cadherin, FZD - Frizzled protein, GPCR - G protein coupled receptor, GSK3 - glycogen synthase 3, ISC - intestinal stem cell, KO - knock out, KRAS — Kirsten rat sarcoma, LATS1/2 — large

\footnotetext{
Correspondence address: P.M. Wierzbicki, Ph.D.

Department of Histology, Faculty of Medicine

Medical University of Gdansk

Debinki St. 1, 80-211 Gdansk

tel.:+48 5834915 01, +485834914 37, fax: +48583491419

e-mail: pwierzb@gumed.edu.pl
}

tumor suppressor kinase 1/2, Lgr5 - leucine-rich repeat-containing GPCR5, LPR - Lipoprotein receptor-related protein, MOB1 - MOB kinase activator 1, MST1/2 - serine/threonine kinase 4/3, NF2 - neurofibromin 2, Oct-4 - octamer-binding transcription factor 4, RASSF - Ras association (RalGDS/AF-6) family member, SAV1 - Salvador family WW domain containing protein 1, STRIPAK - striatin interacting phosphate and kinase complex, TAZ - tafazzin, TCF4 - transcription factor 4 , TEAD - TEA domain family member, TJ — tight junction, $\beta$-TrCP $-\beta$-transducin repeat-containing protein, VEGF - vascular endothelial growth factor, WB - Western blot technique, YAP1 - Yes-associated protein 1

\section{Colorectal cancer}

Colorectal cancer (CRC) is the third most commonly diagnosed cancer in males and the second in females, with an estimated 1.4 million cases and 693,900 deaths occurring in 2012 [1]. Five-year relative survival ranges 


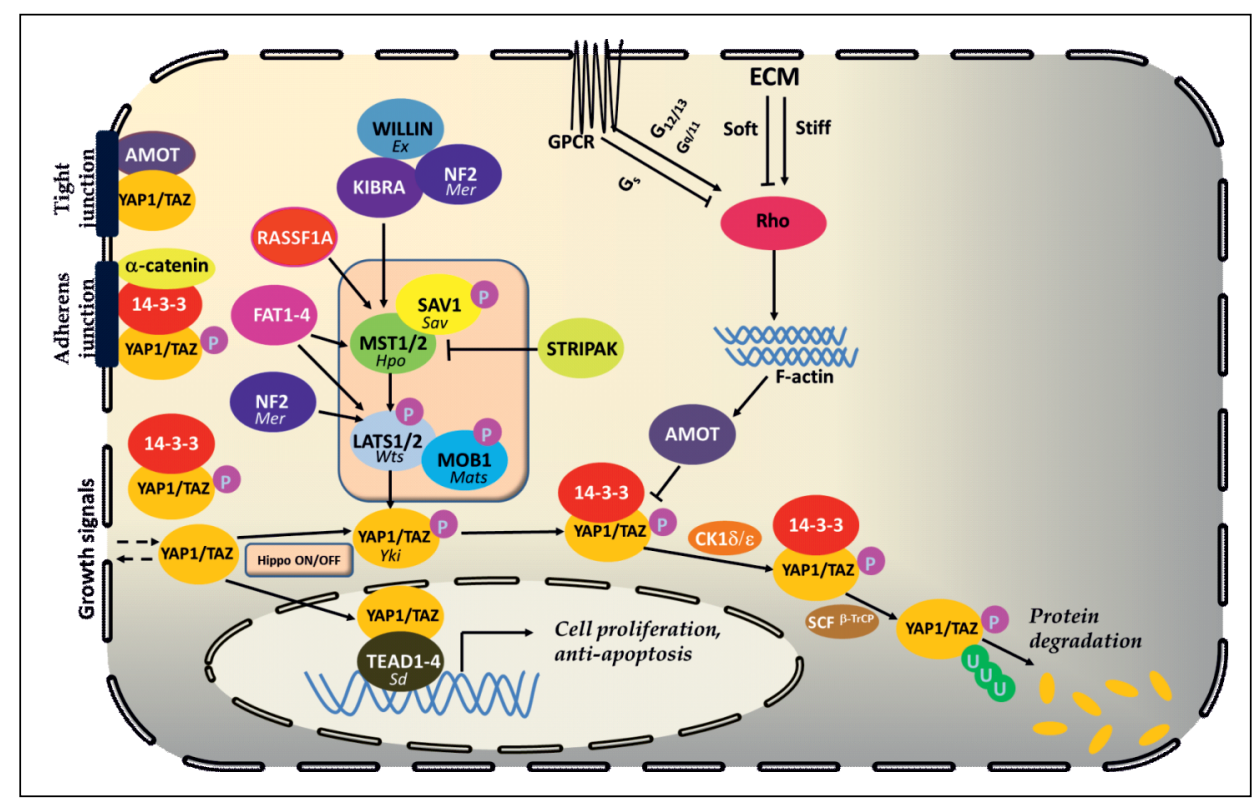

Figure 1. The mammalian Hippo pathway. Drosophila orthologue genes are shown below the names of the mammalian proteins. When the Hippo pathway is not active (e.g. during cell injury and repair or in cancer), the active effector proteins, YAP1 and TAZ, interact with TEAD1-4 transcription factors and promote transcription of genes involved in cell proliferation. During normal cell homeostasis, when the Hippo pathway is active, YAP1 or TAZ are inhibited due to their phosphorylation by core components of the Hippo pathway (SAV1, MST 1/2, LATS1/2 - shown in the central rectangle). In a phosphorylated form cytoplasmic YAP1/TAZ may interact with (i) the 14-3-3 protein, (ii) components of cell junctional complexes like AMOT or $\beta$-catenin, or (iii) may be degraded in proteasomes. YAP1/TAZ can be also regulated by other mechanisms such as cell polarity, GPCR signalling or ECM stiffness as described in the body text. Acronyms are explained on the first page

from more than $90 \%$ in patients with stage I disease to about $10 \%$ in patients with stage IV disease [2]. Treatment of CRC is one of the most expensive when diagnosed at later stages when prognosis is generally poor [3]. Although the knowledge of the background and the development of CRC has recently increased, there is a high need for more studies to found out well working prognostic, survival and diagnostic markers. Serum markers for routine CRC diagnostic such as CEA (carcinoembryonic antigen) and CA 19-9 showed good prognostic values and have been used as CRC tumour predictors [4]. The aim of this paper was to provide rationale to consider the expression of Hippo pathway genes as possible new prognostic genes in CRC.

The modern chemotherapy has adapted molecular findings in many cancers to focus on activation/ /inactivation of cancer-related intracellular pathways to eliminate or decrease expansion of tumour cells. Such drugs which target vascular endothelial growth factor-A (VEGF, Bevacizumab) or epidermal growth factor receptor (EGFR, Cetuximab and Panitumumab) have been introduced for the treatment of CRC [5]. However, it was noted that $50-70 \%$ of advanced CRC cases were resistant to both classical chemotherapeu- tics and so called biological drugs [6]. In this review we also aimed to bring closer the possible associations between the Hippo pathway and drug resistance of CRC cells.

\section{The Hippo pathway}

The Hippo pathway is an important regulator of cell proliferation, growth and apoptosis [7, 8]. Moreover, it controls tissue homeostasis, organ size and stem cell functions. Its deregulation is frequently observed in many human cancers, suggesting that alterations of Hippo signalling are connected with tumour initiation and/or progression [9-11]. Hyperactivation of the Hippo pathway downstream effectors - YAP1 (Yes-associated protein 1) and TAZ (transcriptional co-activator with PDZ binding motif) may contribute to the development of cancer, however, their activation may also play a positive role in stimulating tissue repair and regeneration following injury $[12,13]$. The general scheme of the Hippo pathway and interactions of mammalian Hippo components with upstream signals and effectors are presented in Figure 1 and listed in Table 1. 
Table 1. Names and main functions of the most important Hippo pathway genes and proteins

\begin{tabular}{|c|c|c|c|}
\hline Mammalian gene & Drosophila gene, protein & Protein name, aliases & Protein function \\
\hline$N F 2$ & Mer, Merlin & $\begin{array}{l}\text { Neurofibromin 2, Merlin, ACN, } \\
\text { SCH, BANF }\end{array}$ & $\begin{array}{l}\text { Signal transduction between cell-membrane } \\
\text { and cytoskeletal proteins }\end{array}$ \\
\hline$W W C 1$ & Kibra, ortholog & $\begin{array}{l}\text { WW and C } 2 \text { domain containing } 1 \text {, } \\
\text { KIBRA, HBEBP } 3 \text {, HBEBP36 }\end{array}$ & $\begin{array}{l}\text { Phosphoprotein involved in cell polarity, } \\
\text { mitosis and cell migration [105] }\end{array}$ \\
\hline FRMD6 & Ex, Expanded & $\begin{array}{l}\text { FERM domain containing } 6 \text {, EX1, } \\
\text { Willin }\end{array}$ & $\begin{array}{l}\text { Protein linking cytoskeleton with plasma } \\
\text { membrane [106] }\end{array}$ \\
\hline STK4 & \multirow[t]{2}{*}{ Hро, Hippo } & $\begin{array}{l}\text { Serine/threonine kinase } 4 \text {, } \\
\text { MST1, KRS2 }\end{array}$ & $\begin{array}{l}\text { Cytoplasmic kinase involved in stress- } \\
\text {-induced mitogen-activated protein kinase } \\
\text { cascade }\end{array}$ \\
\hline STK3 & & $\begin{array}{l}\text { Serine/threonine kinase 3, } \\
\text { MST2, KRS1 }\end{array}$ & $\begin{array}{l}\text { Kinase activated by proapoptotic molecules } \\
\text { for the promotion of chromatin condensation } \\
\text { during apoptosis, cardiomyocyte prolifera- } \\
\text { tion [107], regulation of osteoblast/osteoclast } \\
\text { differentiation [108] }\end{array}$ \\
\hline$R A S S F 1$ & & $\begin{array}{l}\text { Ras association (RalGDS/AF-6) } \\
\text { domain family member } 1 \text {, } \\
\text { RASSF1A, NORE2A }\end{array}$ & $\begin{array}{l}\text { Signal transducer, microtubule stabilization, } \\
\text { cell cycle arrest [109] }\end{array}$ \\
\hline$S A V 1$ & Sav, Salvador & $\begin{array}{l}\text { Salvador family WW domain } \\
\text { containing protein } 1, \text { SAV, WW } 45\end{array}$ & $\begin{array}{l}\text { Regulation of protein degradation, RNA } \\
\text { splicing and DNA transcription }\end{array}$ \\
\hline LATS1 & \multirow[t]{2}{*}{ Wts, Warts } & $\begin{array}{l}\text { Large tumour suppressor kinase } 1 \text {, } \\
\text { WARTS }\end{array}$ & $\begin{array}{l}\text { Serine/threonine kinase involved in mitosis: } \\
\text { interacts with } \mathrm{CDC} 2 / \text { cyclin A }\end{array}$ \\
\hline LATS2 & & $\begin{array}{l}\text { Large tumour suppressor kinase } 2 \text {, } \\
\text { KPM }\end{array}$ & $\begin{array}{l}\text { Kinase which interacts with centrosomal pro- } \\
\text { teins aurora-a and ajuba during mitosis [110] }\end{array}$ \\
\hline$M O B 1 A$ & Mats & $\begin{array}{l}\text { MOB kinase activator } 1 \mathrm{~A}, \mathrm{MOB} 1 \text {, } \\
\text { MATS, }\end{array}$ & $\begin{array}{l}\text { Protein involved in mitotic exit network [111], } \\
\text { microtubule stability control [112] }\end{array}$ \\
\hline YAP1 & \multirow[t]{2}{*}{$Y k i$} & Yes-associated protein 1, YAP, YKI & $\begin{array}{l}\text { Downstream effector of Hippo pathway } \\
\text { involved in development, repair and homeo- } \\
\text { stasis }\end{array}$ \\
\hline$T A Z$ & & Tafazzin, EFE, Taz1 & $\begin{array}{l}\text { Non-specific phospholipid-lysophospholipid } \\
\text { transacylase involved in cardiolipin } \\
\text { turnover [113] }\end{array}$ \\
\hline
\end{tabular}

\section{Discovery and function of the Hippo pathway in Drosophila}

The Hippo pathway was first described almost 20 year ago as a result of screening for mutant tumour suppressors in Drosophila. It was found that loss-of-function mutation of the Hippo pathway components revealed enormous overgrowth of fruit flies as a result of increased cell proliferation and decreased apoptosis [14]. The first identified elements of the pathway were its core components: warts (wts), hippo (hpo) and salvador (sav) (Figure 1) [14-17]. These genes belong to the hyperplastic group of Drosophila tumour suppressors, wherein mutations of these genes result in robust tissue overgrowth without alterations of cell differentiation status or cell polarity [18]. Further studies indicated that Hpo kinase in association with its adaptor protein Sav, phosphorylates and activates complex formed by Wts kinase, which is associated with an activating subunit Mats [19]. The kinase activity of Hpo could be antagonised by dSTRIPAK - phosphatase complex [20]. The core kinase cassette of the Hippo pathway acts as a suppressor of a downstream element - Yorkie (Yki) [21]. Subsequent biochemical studies showed that Wts directly phosphorylates and inhibits Yki. Yki is a transcriptional co-activator that lacks DNA binding domain. It cooperates with nuclear transcription factors, like Scalloped, and enables transcription of genes which promote cell proliferation (e.g., Myc) and inhibits apoptosis (e.g., diap1) [22, 23]. When the cell receives growth inhibiting signals, i.e. due to contact inhibition, it activates core components of the pathway that phosphorylate Yki. This leads to the cytoplasmic sequestration of Yki and its binding to the 14-3-3 protein, which finally results in Yki protein degradation $[21,24]$. 


\section{The components and function of the Hippo pathway in mammals}

The core kinases cassette and downstream effectors of the Drosophila Hippo pathway are highly conserved in mammals (Figure 1): MST 1/2 (homologues of Hpo), SAV1 (Sav homologue), LATS 1/2 (Wts homologues), MOB1 (homologues of Mats) and YAP1 and its paralogue TAZ (homologues of Yki) [25]. It was shown that expression of human genes can rescue the phenotypes of corresponding Drosophila mutants in vivo [15, 19,21]. The first kinase MST1/2 can be activated in two different ways: (1) by caspase-dependent cleavage under apoptotic stress [26], or (2) by binding to one of Ras association domain family (RASSF) proteins, RASSF1A [27]. Activated MST1/2 interacts with SAV1 through the SARAH domains presented on both proteins what leads to the phosphorylation and activation of their direct substrates LATS1/2 [28]. MOB1 protein is also phosphorylated by MST1/2, which results in its enhanced interaction with LATS1/2 and formation of a complex that phosphorylates and inhibits activity of YAP1 and/or TAZ (Figure 1) [28, 29].

LATS1/2-dependent phosphorylation of Ser127 of YAP1 and Ser89 of TAZ in sequences HXRXXS (H-histidine; R-arginine; S-serine; $\mathrm{X}$-any amino acid) are the most important reactions within this mechanism since this results in binding of 14-3-3 sites and causes segregation of YAP1 and TAZ in the cytoplasm [30-32]. When LATS1/2 phosphorylates Ser397 of YAP1 and Ser311 of TAZ, casein kinase $1 \varepsilon / \delta$ subsequently phosphorylates Ser400 and Ser403 of YAP1 and Ser314 of TAZ thereby leading to ubiquitination and degradation of YAP1 and TAZ proteins [31]. However, it has to be noted that many other kinases, not involved in the Hippo pathway, can phosphorylate YAP1 in a specific way, depending on the signals received by the cell. Akt kinase, a pro-survival kinase, was shown to negatively regulate the YAP1-dependent transcription of pro-apoptotic genes [31]. It was also found that after DNA damage, c-Abl kinase phosphorylates YAP1 at Y407 (tyrosine phosphorylation) which enhances the YAP1-p73 interaction, prevents Itch-mediated ubiquitination of $\mathrm{p} 73$ and activates transcription of pro-apoptotic genes $[33,34]$.

\section{Regulation of the YAP1/TAZ activity}

Upstream regulators of YAP1/TAZ activity can act either through Hippo pathway core components or independently of Hippo kinases. For instance, in the epithelial cells apical-basal polarity and planar cell polarity regulate the Hippo pathway. In Drosophila epithelium apically localized Merlin (Mer), Expanded (Ex) and Kibra proteins form a complex (Figure 1) which acts by binding to Sav, Hpo and Wts to activate the Hippo pathway in a cooperative manner or via direct binding of Ex and Yki to restrain Yki level in cytoplasm and inhibit its transcriptional activity $[35,36]$.

Function of this apical protein complex is conserved also in mammals. The complex of Nf2 (neurofibromin2, a Mer ortholog), KIBRA and FRMD6 (also known as WILLIN, as potential Ex ortholog) inhibits YAP1 activity (Figure 1) [37]. Nf2, a tumour suppressor gene is currently the only one known Hippo pathway gene that is mutated in cancer (Table 2) [10], especially in cancers of central nervous system [38].

Planar cell polarity not only regulates the position of a cell in the epithelial layer, but also plays a crucial role in the control of development. In Drosophila the protocadherins Fat $(\mathrm{Ft})$ and Dachsous (Ds) modulate Wts activity; however, the role of their mammalian orthologues in the Hippo pathway is not so well understood and requires further studies [39].

Tight junctions (TJ) and adherens junctions (AJ) play an important role in intercellular contacts being responsible for the permeability barriers. Structural proteins of TJ and AJ were shown to interact with YAP1 (Figure 1). Cytoplasmic angiomotin (AMOT) proteins can inhibit YAP1/ /TAZ via physical interactions and transfer of the YAP1/AMOT complexes from cytoplasm to tight junctions or actin cytoskeleton (Figure 1). Moreover, AMOT proteins also activate LATS1/2 to phosphorylate YAP [40]. Another TJ protein, $\mathrm{ZO}-2$, was reported to increase nuclear localization of YAP and tight junction localization of TAZ [41, 42]. It was demonstrated that $\alpha$-catenin, a component of adherens junction, together with 14-3-3 protein and phosphorylated form of YAP1 form a complex that inhibits YAP1 activity [43].

It has been shown that YAP1/TAZ activity can also depend on environmental cues such as extracellular matrix stiffness, cell tension, cell attachment/ /detachment [38, 44]. It was observed, that the nuclear localization of YAP/TAZ resulting in TEAD genes' activation was found during proliferation of endothelial and epithelial cells as well as during osteoblast differentiation [38]. In breast cancer (MCF10A) and mouse fibroblast NIH-3T3 cell cultures it was found that YAP1 overexpression and phosphorylation can overcome cell contact inhibition [29]. Recent reports appraise the role of $\mathrm{G}$ protein-coupled receptors (GPCRs) and their cooperation with Rho GTPase and actin cytoskeleton in negative or positive modifications of YAP1 or TAZ activity. Depending on the class of $G$ proteins, but also on the type of their ligands, the effects on YAP1/TAZ activity regulation might be completely different. For instance, lysophosphatidic acid, sphingosine 1-phosphate and peptide agonists of thrombin receptors induce, whereas 
Table 2. The involvement of Hippo pathway proteins in human diseases

\begin{tabular}{|c|c|c|}
\hline Gene's name & Role in human diseases & Role in CRC development \\
\hline NF2, Merlin & $\begin{array}{l}\text { Mutation leads to neurofibromatosis type II; } \\
\text { lesions in the CNS and eyes and skin [114, 115] } \\
\text { TSG in some cancers due to mutation } \\
\text { and underexpression [10] }\end{array}$ & Barely studied; point mutations were not critical [49] \\
\hline$W W C 1, K I B R A$ & $\begin{array}{l}\text { Polymorphisms associated with Alzheimer's } \\
\text { disease [116] }\end{array}$ & Not studied \\
\hline $\begin{array}{l}\text { FRMD6, human } \\
\text { Expanded }\end{array}$ & $\begin{array}{l}\text { Polymorphisms associated with Alzheimer's disease } \\
\text { [117], CCL: downregulation leads to resistance } \\
\text { to Taxol I MC10FA cells [118] }\end{array}$ & Not studied \\
\hline $\begin{array}{l}\text { STK4, MST1 and } \\
\text { STK3, MST2 }\end{array}$ & $\begin{array}{l}\text { Phosphorylation loss of function in prostate cancer } \\
\text { [119], CCL: overexpression inhibits cell proliferation } \\
\text { and promote apoptosis in HepG2 cells [87] } \\
\text { Mouse double KO: cholangiocarcinoma [46, 101], } \\
\text { HCC [120] }\end{array}$ & $\begin{array}{l}\text { Decreased mRNA level in tumour associated with } \\
\text { node metastasis [121], mouse double KO: crypt } \\
\text { dysplasia, colon adenoma }[46,78,120]\end{array}$ \\
\hline$R A S S F 1, R A S S F 1 A$ & $\begin{array}{l}\text { TSG: promoter hypermethylation and decrease } \\
\text { expression in cancer: thyroid [122], oesophageal [123], } \\
\text { prostate [124], colorectal, breast [125] }\end{array}$ & $\begin{array}{l}\text { TSG; promoter hypermethylation and decrease } \\
\text { expression in CRC }[126,127]\end{array}$ \\
\hline SAV1, Salvador & $\begin{array}{l}\text { TSG: LOH and downregulation in renal cell carcino- } \\
\text { ma [128], no gene mutation in stomach, liver and lung } \\
\text { cancer [129] } \\
\text { CCL: overexpression induces apoptosis in MCF-7 } \\
\text { cells [130] }\end{array}$ & No gene mutation in CRC [129] \\
\hline LATS1 & $\begin{array}{l}\text { TSG: decrease expression in cancer: glioma [131], } \\
\text { NSLC [132], sarcoma [133] and astrocytoma [134]. } \\
\text { CCL: LATS1 degradation inhibits apoptosis } \\
\text { in MCF10A cells [135] }\end{array}$ & $\begin{array}{l}\text { TSG: promoter hypermethylation and mRNA } \\
\text { decrease in CRC [86] }\end{array}$ \\
\hline LATS2 & $\begin{array}{l}\text { TSG: decrease expression in: malignant mesothelioma } \\
\text { (and LOH) [136], NSLC (no mutation found) [137] } \\
\text { and astrocytoma [134] } \\
\text { OG: overexpression in AML [138], nosopharyngeal } \\
\text { carcinoma [139] }\end{array}$ & TSG: downregulation in CRC [87] \\
\hline MOB1, Mob1 & $\begin{array}{l}\text { Targeted by NS5A protein of hepatitis C virus [140]. } \\
\text { Mouse KO: various cancer types developed [141] }\end{array}$ & TSG: downregulation in CRC [142] \\
\hline$T A Z$ & $\begin{array}{l}\text { Mutations in Barth syndrome [143] } \\
\text { OG: overexpression in breast cancer [144], HCC [145] }\end{array}$ & OG: overexpression in CRC [85] \\
\hline$Y A P 1$ & $\begin{array}{l}\text { OG: overexpression in NSCLC [88], prostate [90], } \\
\text { breast [91], gallbladder cancer [146] and glioma [89] } \\
\text { TSG: decreased expression in breast cancer [92] }\end{array}$ & $\begin{array}{l}\text { OG: overexpression in CRC [83], in CRC cases } \\
\text { resistant to cetuximab [102] } \\
\text { TSG: underexpression in CRC [79] }\end{array}$ \\
\hline
\end{tabular}

AML — acute myeloid leukaemia; CCL — cancer cell line(s); HCC — hepatocellular carcinoma; KO — knock out; LOH — loss of heterozygosity; NSCLC — non-small cell lung cancer; OG — oncogene; TSG — tumour suppressor gene

epinephrine or glucagon repress YAP1/TAZ activity $[45,46]$. YAP1 could also be regulated by matrix stiffness independently from LATS1/2 phosphorylation. In cells cultured in soft matrix YAP and TAZ become phosphorylated even if all known LATS1/2 phosphorylation-dependent sites in YAP protein are inactivated by mutations $[47,48]$.

\section{Hippo pathway cross talk with Wnt $/ \beta$-catenin and EGFR/KRAS signalling}

The above presented ways of YAP1/TAZ activity regulation show the complexity of molecular inter- actions within the Hippo pathway. Moreover, cross talks of the Hippo pathway with other signalling pathways like Notch, EGF or Sonic hedgehog have also been described [49]. Due to the space constraints they will not be discussed. However, in this review we focus on the relationships between Hippo and Wnt- $\beta$ catenin signalling pathways because of their crucial role for the maintenance of intestinal epithelium homeostasis (Figure 2A). Additionally, we will also discuss cross talk between Hippo and EGFR/KRAS signalling pathways since their interactions may be involved in drug resistance during CRC chemotherapy (Figure 3) [50,51]. 


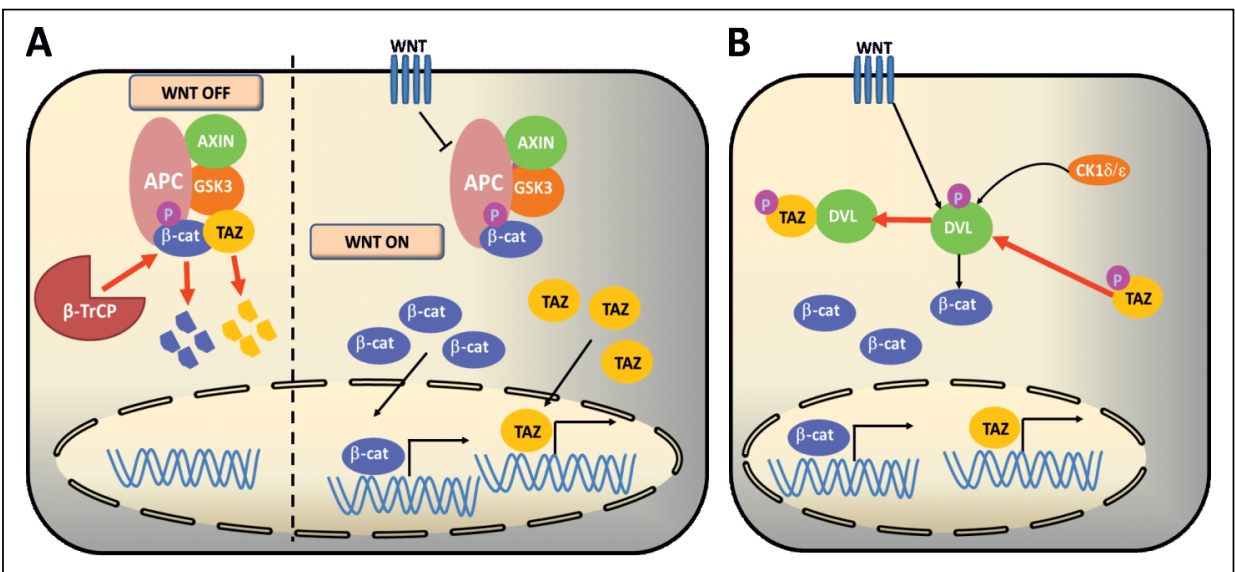

Figure 2. Interactions between Hippo pathway effectors TAZ and YAP and Wnt/ $\beta$-catenin pathway. A. When Wnt pathway is not triggered (WNT OFF), $\beta$-catenin and TAZ are inactivated by degradation via destruction complex. When Wnt is triggered (WNT ON), e.g. during tissue regeneration, the destruction complex is bound to Wnt/Frizzled and LRP5/6 resulting in the inhibition of either $\beta$-catenin or TAZ degradation. This leads to the accumulation of $\beta$-catenin and/or TAZ in the nucleus [38, 57-59]; B. Wnt/ $\beta$-catenin pathway is restricted by TAZ inhibition. On the contrary, YAP1 gene expression is enhanced by $\beta$-catenin/TCF4 complex [60]

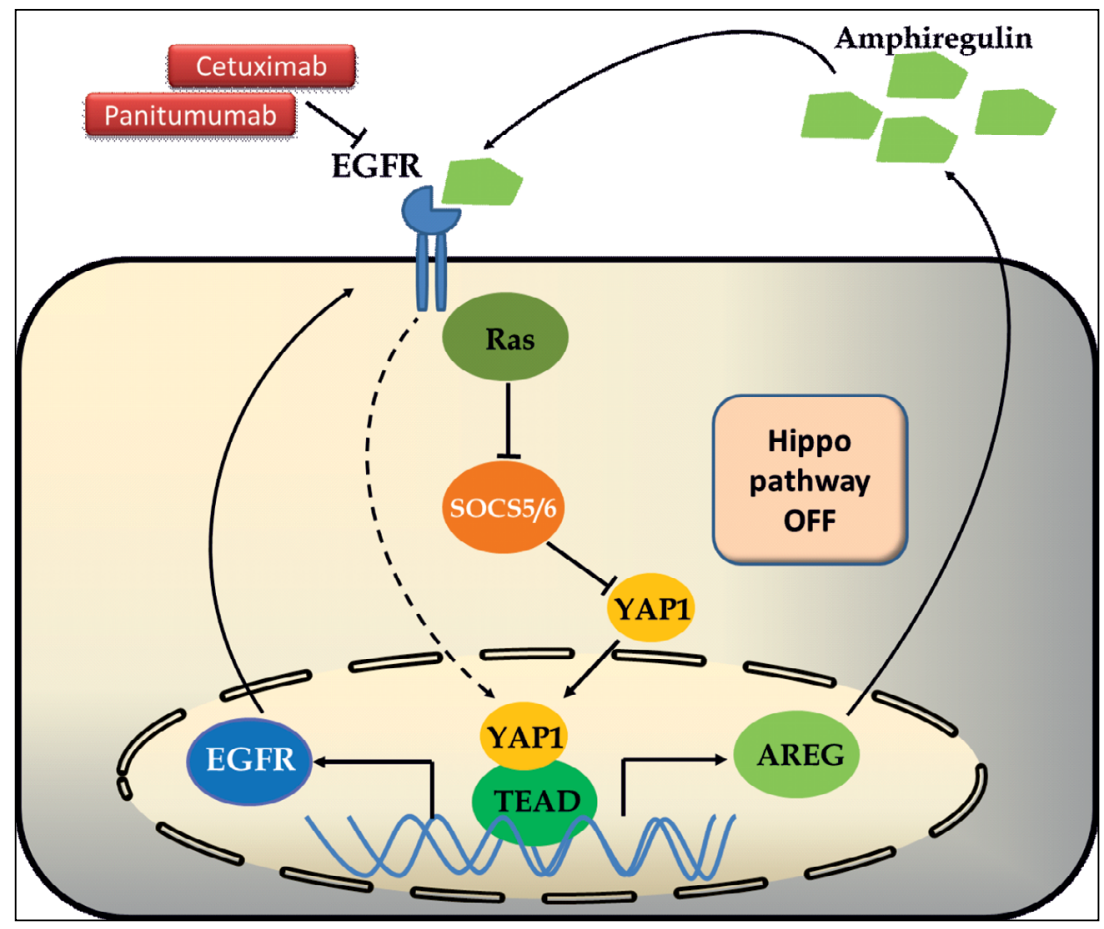

Figure 3. Indirect relationship between EGFR/KRAS and YAP. A positive autocrine regulation between EGFR and YAP1 is established via amphiregulin expression [50,61]. Cetuximab and Panitumumab are humanized monoclonal antibodies against EGFR used in CRC therapy [61]

\section{The interactions of the Hippo and Wnt signalling pathways}

Organs grow up to pre-defined size and shape, which are controlled by different signalling pathways that receive external signals and translate them into respective cellular processes. Cell-cell junctions, cell adhesion, cell polarity, growth factors or other small signalling molecules, like hormones and cytokines, control whether a cell should enter process of proliferation, apoptosis or differentiation. Several studies have emphasized the critical role of the Wnt/ $\beta$-catenin pathway for gastrointestinal (GI) tract homeostasis. Uncovering its interactions with Hippo pathway 
increased our understanding of the mechanisms of intestinal epithelium homeostasis in physiology and pathology [38].

The effector of the Wnt signalling (WNTS) pathway is the transcriptional co-activator $\beta$-catenin [52]. WNTS ligands include many types of proteins that act as morphogens, controlling cell differentiation and proliferation. These molecules bind to cell membrane receptor complexes composed of Frizzled (FZD) and Lipoprotein receptor-related (LPR) proteins and thereby regulate the activity of $\beta$-catenin $[38,53,54]$. $\beta$-catenin plays a central role in several developmental processes, such as regulation of gene transcription [53], stem cell renewal [55] and epithelial-to-mesenchymal transition (EMT) [56]. When a cell does not receive WNT signals, $\beta$-catenin is maintained at low level in the cytoplasm through its degradation in AXIN destruction complex. This complex is composed of the scaffolding protein AXIN, the tumour suppressor adenomatous polyposis coli gene product (APC), casein kinase 1 (CK1) and glycogen synthase 3 (GSK3) [38, 53, 57, 58]. Due to sequential CK1 and GSK3 phosphorylation of $\beta$-catenin $\mathrm{N}$-terminal region, the phosphorylated $\beta$-catenin could be recognized by $\beta$-TrCP, an E3 ubiquitin ligase subunit so that subsequent $\beta$-catenin ubiquitination leads to its proteasomal degradation (Figure 1 and $2 \mathrm{~A}$ ). Continuous elimination of $\beta$-catenin prevents it from nuclear translocation, and thereby Wnt target genes are repressed by the DNA-bound T cell factor/lymphoid enhancer factor, belonging to the TCF/LEF family of transcriptional factors [54].

Binding of Wnt ligand induces the formation of a complex composed of FZD receptor, LRP5/6 co-receptor and WNT ligand together with the recruitment of the scaffolding protein Dishevelled (DVL) [54]. In effect, since $\beta$-catenin is not degraded, it accumulates in the cytoplasm and migrates to nucleus, where it forms a complex with TCF/LEF what enables transcription of Wnt target genes [38, 53, 59].

In 2010 Varelas et al. found that activation of the Hippo pathway restricts $\mathrm{Wnt} / \beta$-catenin signalling by interaction of TAZ and DVL in the cytoplasm (Figure 2B) [60]. TAZ interaction with DVL inhibits CK1 binding and Wnt3A-induced DVL phosphorylation, thereby inhibiting Wnt3A-induced transcriptional response. Loss of TAZ in a cell culture and in the kidneys of Taz-null mice results in increased DVL2 phosphorylation, enhanced cytoplasmic and nuclear $\beta$-catenin accumulation and Wnt-target genes' induction [60]. Furthermore, the inhibition of the Hippo pathway activity leads to increased nuclear TAZ level so that reduced TAZ-DVL binding results in increased target gene expression in both pathways (Figure 2B) [60].

\section{Hippo upregulates EGFR/KRAS pathway}

Recent reports [50, 61-63] revealed that the Hippo pathway effector, YAP1 protein, is involved in the regulation of EGFR/KRAS signalling (Figure 3). During homeostasis, degradation of YAP1 is triggered by ubiquitin ligase complex substrate recognition factors SOCS5/6. It was found that during cancerogenesis EGFR-activated Ras, a small GTP-binding protein, downregulates SOCS5/6 expression, which increases level and half time of YAP1 in the cytoplasm [50]. Non-phosphorylated YAP1 may induce transcription of $E G F R$ as well as $A R E G$ (amphiregulin) genes. Expression of the $E G F R$ gene leads to up-regulation of the above-described positive feedback loop (Figure 3). Moreover, amphiregulin proteins (secretory products of AREG gene) bind to EGFR and act as autocrine growth factors. Such relationship between YAP1 and the EGFR pathway was found to be important in the progression of oesophageal cancer in patients treated with EGFR inhibitors [61]. Recently published results of knockdown of YAP1 and knockdown of ERBB3 study suggested presence of an autocrine loop between YAP1 and EGFR which may control ovarian cell tumourigenesis and cancer progression [63].

\section{The role of the Hippo pathway in intestinal epithelial cells}

\section{Hippo pathway in intestinal epithelium homeostasis}

The inner surface of the intestinal tube is lined with a single layer of epithelial cells that play both absorbing and secreting functions. Major differentiated cell types are enterocytes (which are involved in the uptake of nutrients), goblet cells (which produce mucus), enteroendocrine cells (which produce hormones) and Paneth cells. Except for Paneth cells, all cell types migrate as clonal lineages to the tip of the villus within 4-5 days, where they are shed into the lumen [64]. Post-mitotic Paneth cells are relatively long-lived (5-6 weeks) [65] and intermingle with intestinal stem cells (ISC) at crypt bottoms to secrete ISC niche factors and function in innate immunity. Colon has a simple columnar epithelium that lacks Paneth cells; instead, so called 'deep secretory cells' are thought to be responsible for the ISC niche function [64, 66]. Regardless of the differences in morphology and functions, epithelial cell types in intestinal crypts are organized into three compartments. All epithelial lining cells are derived from intestinal stem cells that occupy the base of crypts ( $1^{\text {st }}$ compartment). ISC divide, migrate and start to differentiate into transient-amplifying cells in the middle of crypts height ( $2^{\text {nd }}$ compartment). 
Transient-amplifying cells finally differentiate into absorptive cells - enterocytes and secretory cells (goblet cells and enteroendocrine cells), which expand from the top third part of the crypt and surface epithelium to the tip of the villus or colon surface epithelium ( $3^{\text {rd }}$ compartment) [67].

The base of intestinal crypts makes a niche for ISCs, where two types of stem cells can be found: cycling crypt base columnar cells (that cycle asymmetrically) and quiescent $(+4)$ cells [68]. Leucine-rich repeat-containing GPCR5 (Lgr5) is a marker present on the crypt base columnar cells, that are intestinal stem cells or long-lived multipotent progenitor cells $[68,69]$. It has been shown that Lgr5 gene is a downstream target of Wnt pathway [69]. Single Lgr5+ stem cell can rebuilt an entire crypt-villus-like structure, but knock-out (KO) of $L g r 5$ gene has no detectable effect on murine intestinal development, probably since other related markers may attain function of the Lgr protein $[68,70]$. For $(+4)$ quiescent cells there are currently no commonly-accepted receptors, however, Bmi1 and Musashi-1 have recently been proposed [71, 72]. Bmi1 expression has been found in distinct cells located near the bottom of crypts, which comprise rarely occurring, slowly cycling cells located predominantly in the +4 position [71]. It was shown that Bmi1+ cells in the situation of conditional Lgr5+ cell deletion, can give rise to Lgr + cells and support crypt-villus regeneration $[71,72]$. On the basis of these and other findings a model in which Lgr5+ cells mediate homeostatic self-renewal, whereas Bmi1 + cells mediate injury-induced regeneration has been proposed [73].

Physiological level of Wnt signalling controls the rate of a crypt proliferation. The elevated level of Wnt signalling is a characteristic feature of ISC in intestinal crypts [64] whereas deregulated Wnt signalling can lead to colorectal cancer development [64]. R-spondin binds to LGR4/LGR5 receptors and enhances WNT signals in ISC, but tumour suppressor RNF43 activity negatively controls WNT signals in ISC by ubiquitinating FZD receptors [74, 75]. Furthermore, Paneth cells constitutively secrete Wnt 3 ligand, but the additional source of Wnt proteins also exists in the surrounding stromal cells. Notch signalling in the intestinal epithelium is involved in inhibition of the secretory phenotype of the differentiating ISC [76].

The relationships between Hippo pathway and Wnt signalling suggest a role of the Hippo pathway in the maintenance of the intestinal epithelium homeostasis. The first reports concerning the Hippo pathway in intestinal epithelium suggested oncogenic role of YAP1. It was demonstrated that endogenous YAP1 is expressed in the base of crypts where the ISCs reside [77]. In the mouse model, when YAP1 was activated in a doxycycline-inducible manner, in contrast to control mice, cell proliferation upon YAP1 activation was observed not only in the base of crypts but extended through the whole length of crypt's epithelium [77]. The experimental inhibition of YAP1's activity resumed differentiation of crypts' epithelial cells. Interestingly, YAP1 activation induced intestinal dysplasia and was associated with high level of nuclear $\beta$-catenin expression, characteristic to active Wnt pathway [77].

\section{The role of Hippo pathway in the regeneration of intestinal epithelium}

The role of YAP1 in tissue regeneration was first described in dextran sodium sulphate (DSS)-induced colon regeneration model. In normal tissue, YAP1 protein is present along the entire crypt in both types of cells: proliferating and post-mitotic [13]. Moreover, conditional YAP1 KO in the intestinal epithelium revealed no visible defects in cell differentiation, cell death, cell proliferation or cell migration along the crypt-villus axis [13]. Five days of DSS treatment of wild-type mice resulted in intestinal inflammation and slightly decreased YAP1 protein level. However, two days after DSS withdrawal, YAP1 protein level dramatically increased. Increased YAP1 protein level was observed (by immunohistochemistry and WB) in regenerating crypts [13]. This study revealed the possibility that Hippo signalling may be constitutively activated during cell and tissue regeneration, however, during normal cell homeostasis YAP1 becomes inactivated. Moreover, the inactivation of tumour suppressors that normally restrict YAP1 function may lead to tumour formation and/or overgrowth of intestinal epithelium [13]. E.g., conditional Sav1 knock-out mice exhibited enlargement of crypts in both colon and small intestine with increased number of proliferating cells. Interestingly this dysplasia was completely diminished by loss of YAP1 [13].

The role of MST1 and MST2 kinases in the intestinal epithelium was also investigated [13, 78]. Ablation of MST1/2 kinases in mouse intestinal epithelium caused marked expansion of stem cell compartment and loss of secretory cells throughout small and large intestine. Decreased phosphorylation, enhanced abundance and nuclear localization of YAP1 were observed as a result of MST1/2 deletion in intestinal epithelium with simultaneous activation of Wnt and Notch signalling [78]. These results correlate with other data obtained upon activation of the nuclear form of YAP1 with mutated LATS1 phosphorylation site [13], because both of 
these conditions lead to the Hippo pathway-independent activation of YAP1.

Divergent views on the role of YAP1 in intestinal tissue regeneration have emerged recently. It has been found that in strong cooperation with Wnt signalling the Hippo pathway controls the regeneration stage after injury. However, cytoplasmic YAP1 restricted elevated Wnt signalling independently of AXIN-APC-GSK complex, and in some cases acted synergistically with the destruction complex to control the subcellular localization of $\beta$-catenin [79]. In mouse overexpression of YAP1 gene inhibited the Wnt-mediated intestinal regeneration and vice versa a loss of YAP1 led to hyperactive Wnt signalling and expansion of stem cell niche during regeneration. It was found that YAP1 nuclear localization correlated with active Wnt signalling whereas its cytoplasmic localization inhibited Wnt pathway [79].

Control of injury-induced proliferation of cells is crucial for maintaining the proper number of cells in the regenerating organ. The insufficient proliferation may lead to atrophy, whereas the dysregulated proliferation may lead to tumourigenesis [80]. For this reason focusing on mechanisms involved in regeneration of such organs like intestine, that is permanently exposed to potentially injuring factors, may provide important clues to the pathomechanisms of uncontrolled cellular proliferation that characterizes neoplasms, including colorectal cancer (Figure 4).

\section{The role of Hippo pathway in colorectal cancer}

Although the most common mutations in CRC involve APC gene and dysregulated $\beta$-catenin signalling, YAP/TAZ can contribute to these mutations [81].

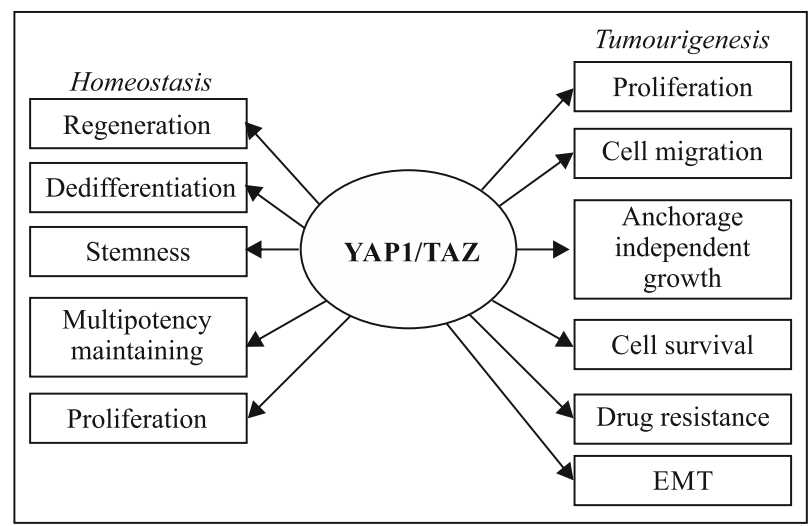

Figure 4. Summary of cellular functions of Hippo pathway effector proteins YAP1/TAZ in intestinal epithelium homeostasis and tumourigenesis
Therefore, expression studies of Hippo pathway components in CRC have been reported by some groups [78, 82-86], however, only Liang et al. presented complex data regarding collaborative expression analysis of the most important Hippo genes [87]. They found decreased mRNA ratios of LATS1 and MST1/2 as well as increased mRNA levels of YAP, TAZ, TEAD and OCT4 in CRC in comparison to healthy colon [87]. Most of the genes coding for the Hippo pathway proteins were shown to function in many types of cancer either as tumour suppressors or as oncogenes (Table 2). The most commonly focused gene, YAP1, was found to be involved in tumour development and progression in different malignancies, including CRC. Although increased level of the YAP1 protein (assessed by WB) was found in most studies [83, 88-91] suggesting its oncogenic role, the under-expression was also observed in breast [92] and colorectal cancer [79]. The study of Barry et al. showed decreased expression of YAP1 in high grade tumours and stage IV [79]. The authors suggested that $Y A P 1$ is a Wnt target gene which plays a role in a negative feedback loop to limit Wnt-initiated signals in CRC development [79].

This hypothesis sheds a new light on the possible role of the Hippo pathway in the Wnt-related pathomechanisms of the CRC development. As previously mentioned, AXIN destruction complex that contains APC protein tightly regulates $\beta$-catenin level in Wnt pathway (Figure 2A). Common mutations in $A P C$ gene are found in most CRC cases [81, 93, 94]. These mutations lead to an elevated $\beta$-catenin level in the cell nucleus where it acts as co-activator of transcription factors of the TCF/LEF family. The expression of the TCF4 transcription factor and the activation of Wnt target genes' transcription by the $\beta$-catenin/ /TCF4 transcription complex were documented in colonocytes [52,95]. It was proved that $\beta$-catenin is required for the YAP1 gene expression in HCT116, an advanced CRC cell line [95]. YAP1 gene silencing in SW620 (colon adenocarcinoma) and HCT116 (metastatic CRC) cell lines resulted in positive regulation of anchorage-independent cell growth, because decreased YAP1 level reduced growth of colonies in soft agar, especially of SW620 cells. YAP1 was detected in the cytoplasm of HCT116, SW620, SW480, RKO, LS174, and HT29 CRC cell lines, which suggests the properly functioning of Hippo pathway kinase cassette [95]. Moreover, WB protein analysis of nuclear and cytoplasmic fractions from cells grown in high confluence revealed that cell density did not affect YAP1 nuclear localization [95]. The analysis of YAP $1 / \beta$-catenin expression in primary and metastatic colorectal tumours revealed that out of the 36 primary tumours examined, $86 \%$ scored positively 
for nuclear localization of $\beta$-catenin and YAP1, while only $3 \%$ lacked nuclear expression of either protein [95]. The distribution was comparable in metastatic CRC tumours, which suggested that $\mathrm{Wnt} / \beta$-catenin signalling pathway and Hippo/YAP1 pathway converge to promote colon cancer [95].

\section{Expression of Hippo pathway components as prognostic factors in colorectal cancer}

Increased expression of YAP1 in CRC was found by many groups $[13,46,78,96]$. E.g., Wang et al. showed that YAP was overexpressed in $52.5 \%(73 / 139)$ of CRC tumours with a predominant localization in the nucleus [97]. Furthermore, YAP1 protein expression in CRC patients correlated with cyclin D levels, nodal status and pTNM stage. The authors proposed that YAP1 may be a prognostic factor in CRC because of the correlation between its high expression and shorter overall survival [97].

Wang et al. also found that YAP1 and TAZ expression levels were significantly associated with the lymph node status in CRC [82]. It is known from other clinical and histopathological studies that have been performed for 25 years in a large surgical centre that the cut-off values of lymph node ratio are strong independent prognostic factors for CRC patients [98]. Therefore, high prognostic impact of lymph node metastases is a background of the statement regarding the role of YAP1 and TAZ in the prognosis of CRC patients [82].

Other reports showed the prognostic value of $Y A P 1$ and $T A Z$ transcription levels for CRC patients. A positive correlation between $T A Z$ and $Y A P 1$ mRNA expression ratios and their downstream target genes $A X L$ and $C T G F$ was found in tumour tissues of 522 CRC patients [85]. In the same study it was demonstrated that $T A Z$, but not YAP mRNA level can be used to predict survival of CRC patients [85]. Increased $T A Z$ mRNA level may not necessarily correlate with the increase of its transcriptional activity since post-translational modifications like phosphorylation may cause its cytoplasmic sequestration. Therefore Yuen et al. proposed to associate $T A Z$ expression with the expression of its two downstream genes, AXL and CTGF. Patients whose tumours overexpressed one, two or all of the three genes had an increasing risk for disease progression [85]. Based on microarray technique, it was also shown that target genes involved in EMT, migration and invasion, colon cancer progression, cancer signalling, angiogenesis and others factors engaged in tumourigenesis, presented differences in their expression level between high and low grade CRC patients which correlated with TAZ-AXL-CTGF expression [85]. Two potential therapeutic targets, $A N O 1$ and $S Q L E$, were also identified: in patients with upregulated $T A Z-A X L$ $C T G F$ expression, a decrease in expression of either $A N O 1$ and SQLE or both genes was associated with the survival of TAZ-AXL-CTGF high grade colon cancer patients [85]. Although the identification of EMT markers can serve as potential prognostic CRC factors, the most recent data suggest caution when interpreting large scale transcriptome data from cancer due to contamination of tumour samples with stromal cells [99].

In a quantitative PCR study which focused on the expression of all Hippo elements in CRC, the mRNA levels of MST1 and LATS2 were decreased to higher extent in colorectal cancer tissues than in colorectal adenomas or adjacent non-tumour tissues (non-tumour tissues $>$ adenomas $>$ cancer) [87]. The mRNA expression levels of $Y A P, T A Z$ and TEAD1 increased in colorectal cancer compared to colorectal adenomas and non-tumour tissues (cancer $>$ adenomas $>$ non-tumour tissues). Similar results were obtained on protein level by WB analysis. The clinicopathologic analysis revealed that expression levels of MST1, LATS2 and CDX2 (Caudal type homeobox transcription factor2, marker of throphoectoderm which plays important roles in endoderm and intestinal development) in patients with lymph node metastasis were significantly lower than those in patients without lymph node metastasis. Finally the mRNA levels of MST1, LATS2 and CDX2 gradually decreased with the TNM stage (I > II > III > IV) and the mRNA levels of $Y A P 1, T A Z$ and TEAD1 gradually increased with TNM (IV > III > II > I) [87].

\section{Associations of Hippo pathway with therapeutic strategies in CRC}

Personalized therapy of advanced cancer was applied as a result of molecular progress in cancer cell biology. Another important reason for personalized therapy in CRC was the occurrence of chemoresistance of tumour cells in some patients when the traditional drug, 5 -fluorouracil $(5 \mathrm{FU})$ was introduced in metastatic CRC therapy [100]. Recent reports on HT29 CRC cell line revealed high level of YAP in 5FU resistant cells. It was found that after exposing the cells to $5 \mathrm{FU}$ YAP became localized in cytoplasmic compartment of cells and phosphorylated causing the cells to enter quiescence. Increased YAP protein levels were also seen in human CRC liver metastases and were correlated with CRC relapse $[43,101]$.

The recently introduced biological drugs act directly on specific cellular targets, mainly growth 
factor receptors. Chemotherapy based on modern molecular-targeting drugs like Cetuximab, Regorafenib or Panitumumab (humanized monoclonal antibodies against EGFR, CEGFR2-TIE2 and EGFR, respectively) showed some efficacy in advanced CRC, but there is only scarce data regarding targeted CRC therapy in respect to the Hippo pathway.

Lee et al. assessed the possible connection between cetuximab-treated CRC patients and YAP1 mRNA expression; patients with CRC were divided into two groups: one group with activated YAP1 in CRC (AYCC) and the second one with inactivated YAP1 in colorectal cancer (IYCC). Statistical analysis revealed that patients with AYCC had slightly more advanced disease than had patients with IYCC (but patients with stage IV were excluded from this analysis). In the group of patients with stage I-III, the AYCC patients demonstrated much shorter survival rates than IYCC patients [102]. During analysis of all tumour stages patients $(n=80)$ who received cetuximab monotherapy, it was found that only in IYCC patients tumour shrinkage (complete or partial remission) occurred. YAP1 activation was significantly associated with poor response to cetuximab therapy in colorectal cancer [102]. Although more studies are necessary, it appears that similarly as in head and neck cancer in which $Y A P 1$ is a potential marker for cetuximab resistance [103], YAP1 expression in colorectal cancer could be regarded as a potential marker of cetuximab therapy effectiveness.

Recently, the association of the EGFR/KRAS pathway with YAP1 expression has been observed in drug-resistant oesophageal cancer [61]. Since the presence of drug-resistant CRC emerged as an important clinical problem [6, 104], we propose that a possible association of the YAP1 expression with the EGFR signalling pathway in CRC should be also studied.

\section{Conclusions}

The Hippo pathway is an evolutionary conserved regulator of cell proliferation, death and differentiation. It controls organ size and tissue homeostasis and acts mainly through inhibition of the activity of YAP1 and TAZ kinases, its major nuclear effectors. The activity of the Hippo pathway can be modulated by cross talk with other signalling pathways such as Wnt or EGFR/ /KRAS which are important in the control of intestinal epithelium's homeostasis. In the intestine, inhibition of the Hippo pathway activity results in stem cell expansion and neoplastic growth. Although core components and their influence on key nuclear effectors are well established, mechanisms that de-regulate the
Hippo pathway, are poorly understood. The available experimental and clinical data strongly suggest that the role of the Hippo pathway should be further explored under different pathological conditions such as cell/tissue injury or neoplastic transformation of intestinal epithelium. Moreover, the possible involvement of the Hippo pathway components in drug resistance of advanced CRC should also be investigated.

\section{Acknowledgment}

The study was supported by grant of the Polish National Science Centre, No. N N402 683940.

\section{References}

1. Torre LA, Bray F, Siegel RL, Ferlay J, Lortet-Tieulent J, Jemal A. Global cancer statistics, 2012. CA Cancer J Clin. 2015;65:87-108. doi: 10.3322/caac.21262.

2. Brenner H, Kloor M, Pox CP. Colorectal cancer. Lancet. 2014;383:1490-1502. doi: 10.1016/S0140-6736(13)61649-9.

3. Sunkara V, Hebert JR. The colorectal cancer mortality-to-incidence ratio as an indicator of global cancer screening and care. Cancer. 2015;121:1563-1569. doi: 10.1002/cncr.29228.

4. Eker B, Ozaslan E, Karaca $\mathrm{H}$ et al. Factors affecting prognosis in metastatic colorectal cancer patients. APJCP. 2015;16:3015-3021. doi: 10.7314/APJCP.2015.16.7.3015.

5. Messersmith WA, Ahnen DJ. Targeting EGFR in colorectal cancer. N Engl J Med. 2008;359:1834-1836. doi: $\underline{10.1056 /}$ NEJMe0806778.

6. Jensen NF, Stenvang J, Beck MK et al. Establishment and characterization of models of chemotherapy resistance in colorectal cancer: Towards a predictive signature of chemoresistance. Mol Oncol. 2015;9:1169-1185. doi: 10.1016/j. molonc.2015.02.008.

7. Zhao B, Lei QY, Guan KL. The Hippo-YAP pathway: new connections between regulation of organ size and cancer. Curr Opin Cell Biol. 2008;20:638-646. doi: 10.1016/j. ceb.2008.10.001.

8. Zhao B, Li L, Lei Q, Guan KL. The Hippo-YAP pathway in organ size control and tumorigenesis: an updated version. Genes Dev. 2010;24:862-874. doi: 10.1101/gad.1909210.

9. Liu H, Jiang D, Chi F, Zhao B. The Hippo pathway regulates stem cell proliferation, self-renewal, and differentiation. Protein Cell. 2012;3:291-304. doi: 10.1007/s13238-012-2919-3.

10. Harvey KF, Zhang X, Thomas DM. The Hippo pathway and human cancer. Nat Rev Cancer. 2013;13:246-257. doi: $10.1038 / \mathrm{nrc} 3458$.

11. Zhao B, Tumaneng K, Guan KL. The Hippo pathway in organ size control, tissue regeneration and stem cell self-renewal. Nat Cell Biol. 2011;13:877-883. doi: 10.1038/ncb2303.

12. Johnson R, Halder G. The two faces of Hippo: targeting the Hippo pathway for regenerative medicine and cancer treatment. Nat Rev Drug Discov. 2014;13:63-79. doi: 10.1038/ $\underline{\operatorname{nrd} 4161 .}$.

13. Cai J, Zhang N, Zheng Y, de Wilde RF, Maitra A, Pan D. The Hippo signaling pathway restricts the oncogenic potential of an intestinal regeneration program. Genes Dev. 2010;24:2383-2388. doi: 10.1101/gad.1978810.

14. Justice RW, Zilian O, Woods DF, Noll M, Bryant PJ. The Drosophila tumor suppressor gene warts encodes a homo$\log$ of human myotonic dystrophy kinase and is required 
for the control of cell shape and proliferation. Genes Dev. 1995;9:534-546. doi: 10.1101/gad.9.5.534.

15. Wu S, Huang J, Dong J, Pan D. hippo encodes a Ste-20 family protein kinase that restricts cell proliferation and promotes apoptosis in conjunction with salvador and warts. Cell. 2003;114:445-456. doi: 10.1038/ncomms7314.

16. Xu T, Wang W, Zhang S, Stewart RA, Yu W. Identifying tumor suppressors in genetic mosaics: the Drosophila lats gene encodes a putative protein kinase. Development. 1995;121:1053-1063. PMID: 7743921.

17. Tapon N, Harvey KF, Bell DW et al. salvador promotes both cell cycle exit and apoptosis in Drosophila and is mutated in human cancer cell lines. Cell. 2002;110:467-478. doi: 10.1016/ S0092-8674(02)00824-3.

18. Hariharan IK, Bilder D. Regulation of imaginal disc growth by tumor-suppressor genes in Drosophila. Annu Rev Genet. 2006;40:335-361. doi: 10.1146/annurev.genet.39.073003.100738.

19. Lai ZC, Wei X, Shimizu T et al. Control of cell proliferation and apoptosis by mob as tumor suppressor, mats. Cell. 2005;120:675-685. doi: 10.1016/j.cell.2004.12.036.

20. Ribeiro PS, Josue F, Wepf A et al. Combined functional genomic and proteomic approaches identify a PP2A complex as a negative regulator of Hippo signaling. Mol Cell. 2010;39:521-534. doi: 10.1016/i.molcel.2010.08.002.

21. Huang J, Wu S, Barrera J, Matthews K, Pan D. The Hippo signaling pathway coordinately regulates cell proliferation and apoptosis by inactivating Yorkie, the Drosophila Homolog of YAP. Cell. 2005;122:421-434. doi: 10.1016/j. cell.2005.06.007.

22. Goulev Y, Fauny JD, Gonzalez-Marti B, Flagiello D, Silber J, Zider A. SCALLOPED interacts with YORKIE, the nuclear effector of the hippo tumor-suppressor pathway in Drosophila. Curr Biol. 2008;18:435-441. doi: 10.1016/i.cub.2008.02.034.

23. Halder G, Johnson RL. Hippo signaling: growth control and beyond. Development. 2011;138:9-22. doi: 10.1242 dev.045500.

24. Ren F, Zhang L, Jiang J. Hippo signaling regulates Yorkie nuclear localization and activity through 14-3-3 dependent and independent mechanisms. Dev Biol. 2010;337:303-312. doi: 10.1016/j.ydbio.2009.10.046.

25. Lei QY, Zhang H, Zhao B et al. TAZ promotes cell proliferation and epithelial-mesenchymal transition and is inhibited by the hippo pathway. Mol Cell Biol. 2008;28:2426-2436. doi: 10.1128/MCB.01874-07.

26. Khokhlatchev A, Rabizadeh S, Xavier R et al. Identification of a novel Ras-regulated proapoptotic pathway. Curr Biol. 2002;12:253-265. doi: 10.1016/S0960-9822(02)00683-8.

27. Chan EH, Nousiainen M, Chalamalasetty RB, Schafer A, Nigg EA, Sillje HH. The Ste20-like kinase Mst2 activates the human large tumor suppressor kinase Lats1. Oncogene. 2005;24:2076-2086. doi: 10.1038/sj.onc.1208445.

28. Oka T, Mazack V, Sudol M. Mst2 and Lats kinases regulate apoptotic function of Yes kinase-associated protein (YAP). J Biol Chem. 2008;283:27534-27546. doi: 10.1074/ jbc.M804380200.

29. Zhao B, Wei X, Li W et al. Inactivation of YAP oncoprotein by the Hippo pathway is involved in cell contact inhibition and tissue growth control. Genes Dev. 2007;21:2747-2761. doi: $10.1101 /$ gad.1602907.

30. Basu S, Totty NF, Irwin MS, Sudol M, Downward J. Akt phosphorylates the Yes-associated protein, YAP, to induce interaction with 14-3-3 and attenuation of p73-mediated apoptosis. Mol Cell. 2003;11:11-23. doi: 10.1016/j.molcel.2008.11.019.
31. Kodaka M, Hata Y. The mammalian Hippo pathway: regulation and function of YAP1 and TAZ. Cell Mol Life Sci. 2015;72:285-306. doi: 10.1007/s00018-014-1742-9.

32. Graves JD, Gotoh Y, Draves KE et al. Caspase-mediated activation and induction of apoptosis by the mammalian Ste20-like kinase Mst1. EMBO J. 1998;17:2224-2234. doi: 10.1093/emboj/17.8.2224.

33. Levy D, Adamovich Y, Reuven N, Shaul Y. The Yes-associated protein 1 stabilizes $\mathrm{p} 73$ by preventing Itch-mediated ubiquitination of p73. Cell Death Differ. 2007;14:743-751. doi: 10.1038/sj.cdd.4402063.

34. Levy D, Adamovich Y, Reuven N, Shaul Y. Yap1 phosphorylation by c-Abl is a critical step in selective activation of proapoptotic genes in response to DNA damage. Mol Cell. 2008;29:350-361. doi: 10.1016/j.molcel.2007.12.022.

35. Hamaratoglu F, Willecke M, Kango-Singh M et al. The tumour-suppressor genes NF2/Merlin and Expanded act through Hippo signalling to regulate cell proliferation and apoptosis. Nat Cell Biol. 2006;8:27-36. doi: 10.1038/ncb1339.

36. Baumgartner R, Poernbacher I, Buser N, Hafen E, Stocker H. The WW domain protein Kibra acts upstream of Hippo in Drosophila.Dev Cell.2010;18:309-316. doi:10.1016/.jevcel.2009.12.013.

37. Angus L, Moleirinho S, Herron L et al. Willin/FRMD6 expression activates the Hippo signaling pathway kinases in mammals and antagonizes oncogenic YAP. Oncogene. 2012;31:238-250. doi: 10.1038/onc.2011.224.

38. Piccolo S, Dupont S, Cordenonsi M. The biology of YAP/ /TAZ: hippo signaling and beyond. Physiol Rev. 2014;94:1287-1312. doi: 10.1152/physrev.00005.2014.

39. Sharma P, McNeill H. Fat and Dachsous cadherins. Prog Mol Biol Transl Sci. 2013;116:215-235. doi: 10.1016/B978-012-394311-8.00010-8.

40. Zhao B, Li L, Lu Q et al. Angiomotin is a novel Hippo pathway component that inhibits YAP oncoprotein. Genes Dev. 2011;25:51-63. doi: 10.1101/gad.2000111.

41. Oka T, Remue E, Meerschaert K et al. Functional complexes between YAP2 and ZO-2 are PDZ domain-dependent, and regulate YAP2 nuclear localization and signalling. Biochem J. 2010;432:461-472. doi: $10.1042 / B j 20100870$.

42. Remue E, Meerschaert $\mathrm{K}, \mathrm{Oka} \mathrm{T}$ et al. TAZ interacts with zonula occludens- 1 and- 2 proteins in a PDZ-1 dependent manner. Febs Lett. 2010;584:4175-4180. doi: 10.1016/j. febslet.2010.09.020.

43. Schlegelmilch K, Mohseni M, Kirak O et al. Yap1 Acts Downstream of alpha-Catenin to Control Epidermal Proliferation. Cell. 2011;144:782-795. doi: 10.1016/j.cell.2011.02.031.

44. Zhao B, Li L, Wang L, Wang CY, Yu JD, Guan KL. Cell detachment activates the Hippo pathway via cytoskeleton reorganization to induce anoikis. Gene Dev. 2012;26:54-68. doi: 10.1101/gad.173435.111.

45. Yu FX, Zhao B, Panupinthu N et al. Regulation of the Hippo -YAP pathway by G-protein-coupled receptor signaling. Cell. 2012;150:780-791. doi: 10.1016/j.cell.2012.06.037.

46. Yu FX, Meng Z, Plouffe SW, Guan KL. Hippo pathway regulation of gastrointestinal tissues. Annu Rev Physiol. 2015;77:201-227. doi: 10.1146/annurev-physiol-021014-071733.

47. Dupont S, Morsut L, Aragona M et al. Role of YAP/TAZ in mechanotransduction. Nature. 2011;474:179-183. doi: 10.1038/nature10137.

48. Aragona M, Panciera T, Manfrin A et al. A mechanical checkpoint controls multicellular growth through YAP/TAZ regulation by actin-processing factors. Cell. 2013;154:1047-1059. doi: $10.1016 /$ i.cell.2013.07.042

49. Zhao B, Li L, Guan KL. Hippo signaling at a glance. J Cell Sci. 2010;123:4001-4006. doi: 10.1242/jcs.069070. 
50. Hong X, Nguyen HT, Chen Q et al. Opposing activities of the Ras and Hippo pathways converge on regulation of YAP protein turnover.EMBOJ. 2014;33:2447-2457. doi: 10.15252/ embj.201489385.

51. Lin L, Sabnis AJ, Chan E et al. The Hippo effector YAP promotes resistance to RAF- and MEK-targeted cancer therapies. Nat Genet. 2015;47:250-256. doi: 10.1038/ng.3218.

52. Mosimann C, Hausmann G, Basler K. Beta-Catenin hits chromatin: regulation of Wnt target gene activation. Nature Rev Mol Cell Biol. 2009;10:276-286. doi: 10.1038/nrm2654.

53. MacDonald BT, Tamai K, He X. Wnt/beta-catenin signaling: components, mechanisms, and diseases. Dev Cell. 2009;17:9-26. doi: 10.1016/j.devcel.2009.06.016.

54. Clevers H. Wnt/beta-catenin signaling in development and disease. Cell. 2006;127:469-480. doi: 10.1016/j.cell.2006.10.018.

55. Sokol SY. Maintaining embryonic stem cell pluripotency with Wnt signaling. Development. 2011;138:4341-4350. doi: 10.1242/dev.066209.

56. Batra H, Antony VB. The pleural mesothelium in development and disease. Front Physiol. 2014;5:284. doi: 10.3389/ fphys.2014.00284.

57. Azzolin L, Zanconato F, Bresolin S et al. Role of TAZ as mediator of Wnt signaling. Cell. 2012;151:1443-1456. doi: 10.1016/j.cell.2012.11.027.

58. Konsavage WM, Yochum GS. Intersection of Hippo/YAP and Wnt/-catenin signaling pathways. Acta Bioch Bioph Sin. 2013;45:71-79. doi: $10.1093 / \mathrm{abbs} / \mathrm{gms} 084$.

59. Azzolin L, Panciera T, Soligo S et al. YAP/TAZ incorporation in the beta-Catenin destruction complex orchestrates the Wnt response. Cell. 2014;158:157-170. doi:10.1016/j.cell.2014.06.013.

60. Varelas X, Miller BW, Sopko R et al. The Hippo pathway regulates Wnt/beta-catenin signaling. Dev Cell.2010;18:579-591. doi: 10.1016/j.devcel.2010.03.007.

61. Song S, Honjo S, Jin J et al. The Hippo coactivator YAP1 mediates EGFR overexpression and confers chemo-resistance in esophageal cancer. Clin Cancer Res. 2015. doi: 10.1158/10780432.CCR-14-2191.

62. Ma L, Ji L, Yu Y, Wang J. Novel molecular targets for diagnosis and treatment of hepatocellular carcinoma. Discov Med. 2015;19:7-14. PMID: 25636956.

63. He C, Lv X, Hua G et al. YAP forms autocrine loops with the ERBB pathway to regulate ovarian cancer initiation and progression. Oncogene. 2015. doi: 10.1038/onc.2015.52.

64. Vermeulen L, Snippert HJ. Stem cell dynamics in homeostasis and cancer of the intestine. Nat Rev Cancer. 2014;14:468-480. doi: $10.1038 / \mathrm{nrc} 3744$.

65. Ireland $\mathrm{H}$, Houghton $\mathrm{C}$, Howard L, Winton DJ. Cellular inheritance of a Cre-activated reporter gene to determine Paneth cell longevity in the murine small intestine. Dev Dyn. 2005;233:1332-1336. doi: $10.1002 /$ dvdy.20446.

66. Rothenberg ME, Nusse Y, Kalisky T et al. Identification of a cKit $(+)$ colonic crypt base secretory cell that supports Lgr5(+) stem cells in mice. Gastroenterology. 2012;142:1195-1205. doi: $10.1053 /$ j.gastro.2012.02.006.

67. Clevers H, Batlle E. SnapShot: the intestinal crypt. Cell. 2013;152:1198-1198e1. doi: 10.1016/j.cell.2013.02.030.

68. Sipos F, Muzes G. Injury-associated reacquiring of intestinal stem cell function. World J Gastroenterol. 2015;21:2005-2010. doi: 10.3748/wjg.v21.i7.2005.

69. Barker N, van Es JH, Kuipers J et al. Identification of stem cells in small intestine and colon by marker gene Lgr5. Nature. 2007;449:1003-1007. doi: 10.1038/nature06196.

70. Sato T, Vries RG, Snippert HJ et al. Single Lgr5 stem cells build crypt-villus structures in vitro without a mesenchymal niche. Nature. 2009;459:262-265. doi: 10.1038/nature07935.
71. Sangiorgi E, Capecchi MR. Bmi1 is expressed in vivo in intestinal stem cells. Nature Genet. 2008;40:915-920. doi: 10.1038/ng.165.

72. Tian H, Biehs B, Warming S et al. A reserve stem cell population in small intestine renders Lgr5-positive cells dispensable. Nature. 2011;478:255-259. doi: 10.1038/nature10408.

73. Yan KS, Chia LA, Li XN et al. The intestinal stem cell markers Bmi1 and Lgr5 identify two functionally distinct populations. PNAS. 2012;109:466-471. doi: 10.1073/pnas.1118857109.

74. de Lau W, Barker N, Low TY et al. Lgr5 homologues associate with Wnt receptors and mediate R-spondin signalling. Nature. 2011;476:293-297. doi: 10.1038/nature10337.

75. Koo BK, Spit M, Jordens I et al. Tumour suppressor RNF43 is a stem-cell E3 ligase that induces endocytosis of Wnt receptors. Nature. 2012;488:665-669. doi: 10.1038/ nature11308.

76. Cao L, Kuratnik A, Xu WL et al. Development of intestinal organoids as tissue surrogates: cell composition and the epigenetic control of differentiation. Mol Carcinogen. 2015;54:189-202. doi: 10.1002/mc.22089.

77. Camargo FD, Gokhale S, Johnnidis JB et al. YAP1 increases organ size and expands undifferentiated progenitor cells. Curr Biol. 2007;17:2054-2060. doi: 10.1016/j.cub.2007.10.039.

78. Zhou D, Zhang Y, Wu $\mathrm{H}$ et al. Mst1 and Mst2 protein kinases restrain intestinal stem cell proliferation and colonic tumorigenesis by inhibition of Yes-associated protein (Yap) overabundance. Proc Natl Acad Sci USA. 2011;108:E1312-E1320. doi: 10.1073/pnas.1110428108.

79. Barry ER, Morikawa T, Butler BL et al. Restriction of intestinal stem cell expansion and the regenerative response by YAP. Nature. 2013;493:106-110. doi: 10.1038/nature11693.

80. Kluwe J, Mencin A, Schwabe RF. Toll-like receptors, wound healing, and carcinogenesis. J Mol Med (Berl). 2009;87:125-138. doi: 10.1007/s00109-008-0426-Z.

81. Plouffe SW, Hong AW, Guan KL. Disease implications of the Hippo/YAP pathway. Trends Mol Med. 2015;21:212-222. doi: 10.1016/j.molmed.2015.01.003.

82. Wang L, Shi S, Guo Z et al. Overexpression of YAP and $\mathrm{TAZ}$ is an independent predictor of prognosis in colorectal cancer and related to the proliferation and metastasis of colon cancer cells. PLoS One. 2013;8:e65539. doi: 10.1371/ journal.pone.0065539.

83. Liu R, Huang S, Lei Y et al. FGF8 promotes colorectal cancer growth and metastasis by activating YAP1. Oncotarget. 2015;6:935-952. doi: 10.1002/wdev.176.

84. Sinha R, Hussain S, Mehrotra R et al. Kras gene mutation and RASSF1A, FHIT and MGMT gene promoter hypermethylation: indicators of tumor staging and metastasis in adenocarcinomatous sporadic colorectal cancer in Indian population. PLoS One. 2013;8:e60142. doi: 10.1371/journal. pone.0060142.

85. Yuen HF, McCrudden CM, Huang YH et al. TAZ expression as a prognostic indicator in colorectal cancer. PLoS One. 2013;8:e54211. doi: 10.1371/journal.pone.0054211.

86. Wierzbicki PM, Adrych K, Kartanowicz D et al. Underexpression of LATS1 TSG in colorectal cancer is associated with promoter hypermethylation. World J Gastroenterol. 2013;19:4363-4373. doi: 10.3748/wjg.v19.i27.4363.

87. Liang K, Zhou G, Zhang Q, Li J, Zhang C. Expression of hippo pathway in colorectal cancer. Saudi J Gastroenterol. 2014;20:188-194. doi: 10.4103/1319-3767.133025.

88. Bora-Singhal N, Nguyen J, Schaal C et al. YAP1 regulates OCT4 activity and SOX2 expression to facilitate self-renewal and vascular mimicry of stem-like cells. Stem Cells. 2015;33:1705-1718. doi: 10.1002/stem.1993. 
89. Liu YC, Wang YZ. Role of Yes-associated protein 1 in gliomas: pathologic and therapeutic aspects. Tumour Biol. 2015;36:2223-2227. doi: 10.1007/s13277-015-3297-2.

90. Machado-Neto JA, Lazarini M, Favaro P et al. ANKHD1, a novel component of the Hippo signaling pathway, promotes YAP1 activation and cell cycle progression in prostate cancer cells. Exp Cell Res. 2014;324:137-145. doi: 10.1016/j. yexcr.2014.04.004.

91. Vlug EJ, van de Ven RA, Vermeulen JF, Bult P, van Diest PJ, Derksen PW. Nuclear localization of the transcriptional coactivator YAP is associated with invasive lobular breast cancer. Cell Oncol (Dordr). 2013;36:375-384. doi: 10.1007/ s13402-013-0143-7.

92. Nourashrafeddin S, Aarabi M, Modarressi MH, Rahmati M, Nouri M. The evaluation of WBP2NL-related genes expression in breast cancer. Pathol Oncol Res. 2015;21:293-300. doi: 10.1007/s12253-014-9820-8.

93. Inra JA, Steyerberg EW, Grover S, McFarland A, Syngal S, Kastrinos F. Racial variation in frequency and phenotypes of APC and MUTYH mutations in 6,169 individuals undergoing genetic testing. Genet Med. 2015. doi: 10.1038/gim.2014.199.

94. Liu XR, Shan XN, Friedl W et al. May the APC gene somatic mutations in tumor tissues influence the clinical features of Chinese sporadic colorectal cancers? Acta Oncol. 2007;46:757-762. doi: 10.1080/02841860600996439.

95. Konsavage WM Jr, Kyler SL, Rennoll SA, Jin G, Yochum GS. Wnt/beta-catenin signaling regulates Yes-associated protein (YAP) gene expression in colorectal carcinoma cells. J Biol Chem. 2012;287:11730-11739. doi: 10.1074/jbc.M111.327767.

96. Steinhardt AA, Gayyed MF, Klein AP et al. Expression of Yes-associated protein in common solid tumors. Hum Pathol. 2008;39:1582-1589. doi: 10.1016/j.humpath.2008.04.012.

97. Wang Y, Xie C, Li Q, Xu K, Wang E. Clinical and prognostic significance of Yes-associated protein in colorectal cancer. Tumour Biol. 2013;34:2169-2174. doi: 10.1007/s13277-0130751-x.

98. Rosenberg R, Friederichs J, Schuster T et al. Prognosis of patients with colorectal cancer is associated with lymph node ratio: a single-center analysis of 3,026 patients over a 25 year time period. Ann Surg. 2008;248:968-978. doi: 10.1097/ SLA.0b013e318190eddc.

99. Kim H, Verhaak RG. Transcriptional mimicry by tumor-associated stroma. Nat Genet. 2015;47:307-309. doi: 10.1038 ng. 3255 .

100. Touil Y, Igoudjil W, Corvaisier M et al. Colon cancer cells escape 5FU chemotherapy-induced cell death by entering stemness and quiescence associated with the $\mathrm{c}-\mathrm{Yes} / \mathrm{YAP}$ axis. Clin Cancer Res. 2014;20:837-846. doi: 10.1158/1078-0432. CCR-13-1854.

101. Zhou D, Conrad C, Xia F et al. Mst1 and Mst2 maintain hepatocyte quiescence and suppress hepatocellular carcinoma development through inactivation of the Yap1 oncogene. Cancer Cell. 2009;16:425-438. doi: 10.1016/j.ccr.2009.09.026.

102. Lee KW, Lee SS, Kim SB et al. Significant association of oncogene YAP1 with poor prognosis and cetuximab resistance in colorectal cancer patients. Clin Cancer Res. 2015;21:357-364. doi: 10.1158/1078-0432.CCR-14-1374.

103. Jerhammar F, Johansson AC, Ceder R et al. YAP1 is a potential biomarker for cetuximab resistance in head and neck cancer. Oral Oncol. 2014;50:832-839. doi: 10.1016/j. oraloncology.2014.06.003.

104. Wei N, Chu E, Wu SY, Wipf P, Schmitz JC. The cytotoxic effects of regorafenib in combination with protein kinase D inhibition in human colorectal cancer cells. Oncotarget. 2015;6:4745-4756. doi: 10.3727/096504014X13946388748910.
105. Zhang L, Yang SP, Wennmann DO, Chen YH, Kremerskothen J, Dong JX. KIBRA: In the brain and beyond. Cellular Signalling. 2014;26:1392-1399. doi: 10.1016/j.cellsig.2014.02.023.

106. Gunn-Moore FJ, Welsh GI, Herron LR et al. A novel 4.1 ezrin radixin moesin (FERM)-containing protein, "Willin". Febs Lett. 2005;579:5089-5094. doi: 10.1016/j.febslet.2005.07.097.

107. Zi M, Maqsood A, Prehar S et al. The mammalian Ste20-like kinase 2 (Mst2) modulates stress-induced cardiac hypertrophy. J Biol Chem. 2014;289:24275-24288. doi: 10.1074/jbc. M114.562405.

108. Lee J, Youn BU, Kim Ket al. Mst 2 controls bone homeostasis by regulating osteoclast and osteoblast differentiation.J Bone Miner Res. 2015. doi: $10.1002 / \mathrm{jbmr} .2503$.

109. Fausti F, Di Agostino S, Sacconi A, Strano S, Blandino G. Hippo and rassf1a pathways: a growing affair. Mol Biol Int. 2012;2012:307628. doi: 10.1155/2012/307628.

110. Yabuta N, Mukai S, Okada N, Aylon Y, Nojima H. The tumor suppressor Lats2 is pivotal in Aurora A and Aurora B signaling during mitosis. Cell Cycle. 2011;10:2724-2736. PMID: 21822051.

111. Stavridi ES, Harris KG, Huyen Y et al. Crystal structure of a human Mob1 protein: toward understanding Mob-regulated cell cycle pathways. Structure. 2003;11:1163-1170. doi: 10.1016/S0969-2126(03)00182-5.

112. Florindo C, Perdigao J, Fesquet D, Schiebel E, Pines J, Tavares AA. Human Mob1 proteins are required for cytokinesis by controlling microtubule stability.J Cell Sci. 2012;125:3085-3090. doi: $10.1242 /$ jes.097147.

113. Schlame M. Cardiolipin remodeling and the function of tafazzin. Biochim Biophys Acta. 2013;1831:582-588. doi: 10.1016/j. bbalip.2012.11.007.

114. Rustgi AK, Xu L, Pinney D et al. Neurofibromatosis 2 gene in human colorectal cancer. Cancer Genet Cytogen. 1995;84:24-26. doi: 10.1016/0165-4608(95)00059-3.

115. Asthagiri AR, Parry DM, Butman JA et al. Neurofibromatosis type 2. Lancet. 2009;373:1974-1986. doi: 10.1016/S01406736(09)60259-2.

116. Wang HF, Tan L, Yu JT, Ma XY, Liu QY, Wang W. Age-dependent association of KIBRA gene polymorphism with Alzheimer's disease in Han Chinese. Mol Biol Rep. 2013;40:7077-7082. doi: 10.1007/s11033-013-2830-x.

117. Hong MG, Reynolds CA, Feldman AL et al. Genome-wide and gene-based association implicates FRMD6 in Alzheimer disease. Hum Mutat. 2012;33:521-529. doi: 10.1002/ humu.22009.

118. Visser-Grieve S, Hao Y, Yang X. Human homolog of Drosophila expanded, $\mathrm{hEx}$, functions as a putative tumor suppressor in human cancer cell lines independently of the Hippo pathway. Oncogene. 2012;31:1189-1195. doi: 10.1038/onc.2011.318.

119. Karamitopoulou E, Zlobec I, Patsouris E, Peros G, Lugli A. Loss of E-cadherin independently predicts the lymph node status in colorectal cancer. Pathology. 2011;43:133-137. doi: 10.1097/PAT.0b013e3283425b7f.

120. Qin F, Tian J, Zhou D, Chen L. Mst1 and Mst2 kinases: regulations and diseases. Cell Biosci. 2013;3:31. doi: 10.1186/20453701-3-31.

121. Rawat SJ, Chernoff J. Regulation of mammalian Ste20 (Mst) kinases. Trends Biochem Sci. 2015;40:149-156. doi: 10.1016/j. tibs.2015.01.001.

122. Brown TC, Juhlin CC, Healy JM, Prasad ML, Korah R, Carling T. Frequent silencing of RASSF1A via promoter methylation in follicular thyroid hyperplasia: a potential early epigenetic susceptibility event in thyroid carcinogenesis. JAMA Surg. 2014;149:1146-1152. doi: 10.1001/jamasurg.2014.1694. 
123. Guo W, Cui L, Wang C et al. Decreased expression of RASSF1A and up-regulation of RASSF1C is associated with esophageal squamous cell carcinoma. Clin Exp Metastasis. 2014;31:521-533. doi: 10.1007/s10585-014-9646-5.

124. Daniunaite K, Jarmalaite S, Kalinauskaite N et al. Prognostic value of RASSF1 promoter methylation in prostate cancer. J Urol. 2014;192:1849-1855. doi: 10.1016/j.juro.2014.06.075.

125. Hagrass HA, Pasha HF, Shaheen MA, Abdel Bary EH, Kassem R. Methylation status and protein expression of RASSF1A in breast cancer patients. Mol Biol Rep. 2014;41:57-65. doi: $10.1007 / \mathrm{s} 11033-013-2837-3$.

126. Cao D, Chen Y, Tang Y et al. Loss of RASSF1A expression in colorectal cancer and its association with K-ras status. Biomed Res Int. 2013;2013:976765. doi: 10.1155/2013/976765.

127. Nilsson TK, Lof-Ohlin ZM, Sun XF. DNA methylation of the p14ARF, RASSF1A and APC1A genes as an independent prognostic factor in colorectal cancer patients. Int J Oncol. 2013;42:127-133. doi: 10.3892/ijo.2012.1682.

128. Matsuura K, Nakada C, Mashio M et al. Downregulation of SAV1 plays a role in pathogenesis of high-grade clear cell renal cell carcinoma. BMC Cancer. 2011;11:523. doi: 10.1186/1471-2407-11-523.

129. Yoo NJ, Soung YH, Lee JW et al. Mutational analysis of salvador gene in human carcinomas. APMIS. 2003;111:595-598. doi: $10.1034 / j .1600-0463.2003 .1110601 . x$.

130. Luo X, Li Z, Li X et al. hSav1 interacts with HAX1 and attenuates its anti-apoptotic effects in MCF-7 breast cancer cells. Int J Mol Med. 2011;28:349-355. doi: 10.3892/ijmm.2011.692.

131. Ji TH, Liu D, Shao W, Yang WS, Wu HQ, Bian XW. Decreased expression of LATS1 is correlated with the progression and prognosis of glioma.J Exp Clin Canc Res. 2012;31:67. doi: 10.1186/1756-9966-31-67.

132. Lin XY, Zhang XP, Wu JH, Qiu XS, Wang EH. Expression of LATS1 contributes to good prognosis and can negatively regulate YAP oncoprotein in non-small-cell lung cancer. Tumour Biol. 2014;35:6435-6443. doi: 10.1007/s13277-014-1826-z.

133. Hisaoka M, Tanaka A, Hashimoto H. Molecular alterations of h-warts/LATS1 tumor suppressor in human soft tissue sarcoma. Lab Invest. 2002;82:1427-1435. doi: 10.1097/01. LAB.0000032381.68634.CA.

134. Jiang Z, Li X, Hu J et al. Promoter hypermethylation-mediated down-regulation of LATS1 and LATS2 in human astrocytoma. Neurosci Res. 2006;56:450-458. doi: 10.1016/j. neures.2006.09.006.
135. Yeung B, Ho KC, Yang XL. WWP1 E3 ligase targets LATS1 for ubiquitin-mediated degradation in breast cancer cells. Plos One. 2013;8. doi: 10.1371/journal.pone.0061027.

136. Murakami H, Mizuno T, Taniguchi T et al. LATS2 is a tumor suppressor gene of malignant mesothelioma. Cancer Res. 2011;71:873-883. doi: 10.1158/0008-5472.CAN-10-2164.

137. Strazisar M, Mlakar V, Glavac D. LATS2 tumour specific mutations and down-regulation of the gene in non-small cell carcinoma. Lung Cancer. 2009;64:257-262. doi: 10.1016/j. lungcan.2008.09.011.

138. Gholami M, Mirfakhraie R, Movafagh A et al. The expression analysis of LATS2 gene in de novo AML patients. Med Oncol. 2014;31:961. doi: 10.1007/s12032-014-0961-0.

139. Zhang Y, Hu CF, Chen J, Yan LX, Zeng YX, Shao JY. LATS2 is de-methylated and overexpressed in nasopharyngeal carcinoma and predicts poor prognosis. BMC Cancer. 2010;10:538. doi: 10.1186/1471-2407-10-538.

140. Chung HY, Gu M, Buehler E, MacDonald MR, Rice CM. Seed sequence-matched controls reveal limitations of small interfering RNA knockdown in functional and structural studies of hepatitis C virus NS5A-MOBKL1B interaction. J Virol. 2014;88:11022-11033. doi: 10.1128/JVI.01582-14.

141. Nishio M, Hamada K, Kawahara K et al. Cancer susceptibility and embryonic lethality in Mob1a/1b double-mutant mice. J Clin Invest. 2012;122:4505-4518. doi: 10.1172/JCI63735.

142. Kosaka Y, Mimori K, Tanaka F, Inoue H, Watanabe M, Mori M. Clinical significance of the loss of MATS1 mRNA expression in colorectal cancer. Int J Oncol. 2007;31:333-338. doi: 10.3892/ijo.31.2.333.

143. Ferri L, Donati MA, Funghini S et al. New clinical and molecular insights on Barth syndrome. Orphanet J Rare Dis. 2013;8:27. doi: 10.1186/1750-1172-8-27.

144. Bartucci M, Dattilo R, Moriconi C et al. TAZ is required for metastatic activity and chemoresistance of breast cancer stem cells. Oncogene. 2015;34:681-690. doi: 10.1038/ /onc.2014.5.

145. Xiao H, Jiang N, Zhou B, Liu Q, Du C. TAZ regulates cell proliferation and epithelial-mesenchymal transition of human hepatocellular carcinoma. Cancer Sci. 2015;106:151-159. doi: $\underline{10.1111 / \text { cas.12587. }}$

146. Li M, Lu J, Zhang F et al. Yes-associated protein 1 (YAP1) promotes human gallbladder tumor growth via activation of the AXL/MAPK pathway. Cancer Lett. 2014;355:201-209. doi: 10.1016/j.canlet.2014.08.036.

Submitted: 3 July, 2015

Accepted after reviews: 8 July, 2015 Available as AoP: 9 July, 2015 